\title{
Short Communication: An insight into protein sequences of PTP-like cysteine phytases
}

\author{
VINOD KUMAR ${ }^{1,2}$, SANJEEV AGRAWAL ${ }^{1, \boldsymbol{v}}$ \\ ${ }^{1}$ Department of Biochemistry, College of Basic Sciences and Humanities, G.B. Pant University of Agriculture and Technology. Pantnagar-263145, India. \\ Tel. +91-5944-233310, Fax. +91-5944-233473, "email: sanjeevagrawal14@ rediffmail.com \\ ${ }^{2}$ Akal School of Biotechnology, Eternal University, Baru Sahib, Sirmour-173101, India.
}

Manuscript received: 26 April 2014. Revision accepted: 30 April 2014.

\begin{abstract}
Kumar V, Agrawal S. 2014. An insight into protein sequences of PTP-like cysteine phytases. Nusantara Bioscience 6: 102106. Protein tyrosine phosphatase-like cysteine phytases (CPhy) are novel phytases reported in the ruminant microbial community and suggested to play major role in phytate-phosphorus hydrolysis in animal feed. These phytases are very promising to be used in animal feed applications for monogastric animals. Present study deals with utilization of sequence information of 40 CPhy reference protein sequences for their sequential characterization for conserved regions, phylogenetic relationship, biochemical features, superfamily and functional motifs therein. The study reveals that CPhy, not well characterized class of phytases, contains conserved sequence feature which may be important catalytic residues. Five major clusters observed in phylogenetic tree with Clostridium sp. as largest cluster. Reported motifs might be used for diversity and expression analysis of CPhy enzymes
\end{abstract}

Keywords. Cysteine phytase, in silico analysis, motifs, phylogenetic tree, phytic acid

\section{INTRODUCTION}

Phytases (myo-inositol 1,2,3,4,5,6-hexakisphosphate phosphohydrolase) are a special group of phosphatases which catalyzes the stepwise removal of phosphates from phytic acid (myo-inositol 1,2,3,4,5,6-hexakisphosphate; $\mathrm{IP}_{6}$ ) or its salt phytate (Lei et al. 2013). It is, therefore, useful in various applications, e.g. alleviating antinutritional effect of phytate in animal feed, increase bioavailability of micronutrients to monogastric animals, management of environmental phosphorus pollution (Sapna et al. 2013) and promising for aquafeed application (Kumar et al. 2014b).

Phytases are widely distributed among plants and microbial cells (Hegeman and Grabau 2001; Kumar et al. 2013; Singh et al. 2014; Lei et al. 2013). To develop a suitable phytase for above applications and better understand the catalytic mechanism of diverse groups of phytases, large number of such organisms has been studied in detail for their phytase gene sequences and biochemical properties. Based on the specific consensus sequence, catalytic mechanism, and three dimensional structures, so far phytases are therefore classified in four classes, i.e. histidine acid phosphatase (HAPhy), cysteine phytase (CPhy), purple acid phosphatase (PAPhy) and betapropeller phytase (BPPhy) (Lei et al. 2007; Mullaney and Ullah 2007; Lei et al. 2013). Further classification based on the site of phytic acid dephosphorylation reveals three groups of phytases, i.e. 3-phytase (alternative name, 1phytase; EC 3.1.3.8), 4-phytase (alternative name, 6phytase; EC 3.1.3.26), and 5-phytase (EC 3.1.3.72) (Kumar et al. 2014a).
Although tremendous work has been carried out related to phytase research, new technologies like sequencing advances, enzyme engineering, proteomics, and related bioinformatic studies have further given a new life to this old enzyme (Lei et al. 2013). In addition to this, in silico characterization of protein sequences of HAPhy and BPPhy class of phytases has been reported recently (Kumar et al. 2012; Kumar et al. 2014a). These studies have been suggested to be useful in further genetic engineering and classification in important groups of phytases. The use and bioinformatic analysis of resulting DNA and protein sequence information from different studies make it possible to get important predictions and help in the design and success of further studies.

Among the different class of phytases, CPhy class is least studied for its biochemical and important sequence catalytic features. Several CPhy has been reported by rumen bacterial isolates, including Megasphaera elsdenii, Clostridium perfringens, and Clostridium botulinum (Yanke et al. 1999). Biochemical characteristic of CPhy has not been studied in detail and very little literature is available on characterization of CPhy. In one such study, CPhy from Selenomonas ruminantium has been studied and characterized extensively by Puhl et al. (2007). In the present study, the 40 reference protein sequences of CPhy from protein databases were retrieved and analyzed 'in silico' for their biochemical features, multiple sequence alignment, and identity search, phylogenetic tree construction, distribution of motifs and superfamily using various bioinformatics tools. 


\section{Materials and methods}

The 40 reference protein sequences representing CPhy from NCBI protein database (http: //www.ncbi.nlm.nih.gov) were retrieved in FASTA format for use in this study (Table 1). The protein sequences, which were shown to exhibit phytase activities, were selected for in silico study. Their characterization for homology, phylogenetic relationship, functional domain, and other biochemical properties was carried out using freely available bioinformatic tools following the methodology of Kumar et al. (2012). For domain search, the Pfam site (http: //www.sanger.ac.uk/software/pfam/search.html) was used. Functional domains and motifs analysis were done using MEME (http: //meme.sdsc.edu/meme/meme.html).

\section{Result and discussion}

The 40 reference sequences representing CPhy with GenBank accession number are listed in Table 1. Two conserved regions 'DLR[E/Q]E[S/T]HG[F/L]' and 'WxHFHCxxGxGRT' were obtained in all representative sequences, when analyzed by multiple sequence alignment using ClustalW by MEGA5 (Tamura et al. 2011). High distinctiveness was observed in cysteine phytase protein sequences during alignment. The primary sequence of this enzyme contains a PTP-like signature sequence $\left(\mathrm{C}(\mathrm{X})_{5} \mathrm{R}\right)$, which is ubiquitous among members of the PTP superfamily (Zhang et al. 2002). All PTPs have a phosphate-binding loop (P-loop) at the base of their active site which contains the characteristic PTP signature sequence $\mathrm{C}(\mathrm{X})_{5} \mathrm{R}$ (Denu and Dixon 1998; Zhang 2003). Site-directed mutagenesis studies have determined that the cysteine residue present in the P-loop is absolutely required for PTP activity (Puhl et al. 2007). It is a strong nucleophile, and is easily modified by thiol reagents (Sechi and Chait 1998). Chemical modification experiments with alkylating agents also indicate that the Ploop cysteine is required for PTP activity (Zhou et al. 1994). PTPs use the nucleophilic cysteine residue to bind the phosphate monoester of the substrate, forming a thiol-phosphate intermediate (Pannifer et al. 1998). S. ruminantium phytase neither contains the conserved RHGXRXP motif nor is affected by divalent metal ions. The active site is located near a conserved cysteinecontaining (Cys241) P loop (Chu et al. 2004).

A total of 5 clusters were observed in phylogenetic tree constructed by the Neighbor-Joining method. The largest cluster ' 1 ' contains sequences from Clostridium sp. (21 sequences). Cluster ' 2 ' was composed of Protochlamydia (YP_008827.1) and Parachlamydia acanthamoebae (ZP_06300753.1). Cluster '3' also contains 2 sequences from Desulfovibrio sp. (YP_002953065.1, ZP_07334842.1). Cluster '4' consists of 13 sequences with majority from Selenomonas sp. and Acidaminococcus sp. Cluster ' 5 ' consisted of Mitsuokella multacida (ZP_05405390.2) and Bdellovibrio bacteriovorus (NP_968118.1) (Figure 1.A and 1.B).

The variations in biochemical features of representing CPhy protein sequences are given in Table 2. The length of protein sequences was found in the range of 283-347 amino acid residues, except 5 sequences from Clostridium sp. were 820 amino acid residues long. The theoretical $\mathrm{pI}$ value of CPhy sequences was observed to be highest among four classes of phytase and was in the range of 7-10. The instability index is used to measure in vivo half life of a protein (Guruprasad et al. 1990). The instability index of 7 CPhy protein sequences was above 40 indicating their low in vivo stability (Table 2), while the rest of the sequences with their instability index value below 40 have in vivo stability of more than $16 \mathrm{~h}$ (Rogers et al. 1986). Aliphatic index of protein measures the relative volume occupied by aliphatic side chains of the amino acids: alanine, valine, leucine, and isoleucine. Globular proteins with high aliphatic index have high thermostability and an increase in

Table 1. List of source organism of retrieved CPhy protein sequences (with accession number)

\begin{tabular}{|c|c|c|}
\hline Source organism & Accession no. & $\begin{array}{c}\text { Total } \\
\text { sequences }\end{array}$ \\
\hline Acidaminococcus fermentans & YP_003399467.1 & 1 \\
\hline Acidaminococcus intestine & YP 004897589.1 & 1 \\
\hline Acidaminococcus sp. & $\mathrm{ZP} 03929107.1$ & 1 \\
\hline Bdellovibrio bacteriovorus & NP_968118.1 & 1 \\
\hline Centipeda periodontii & ZP_08501473.1 & 1 \\
\hline Clostridium acetobutvlicum & NP 149178.1 & 1 \\
\hline Clostridium botulinum & $\begin{array}{l}\text { YP_001787593.1,ZP_02951610.1, } \\
\text { YP_002863193.1, ZP_02614565.1, } \\
\text { YP_001391515.1, YP_001781827.1, } \\
\text { YP_001254710.1 }\end{array}$ & 7 \\
\hline Clostridium kluyveri & YP_001394001.1 & 1 \\
\hline Clostridium ljungdahlii & YP_003781358.1, YP_003781970.1 & 2 \\
\hline Clostridium perfringens & $\begin{array}{l}\text { YP_696211.1, ZP_02633371.1, } \\
\text { NP_562440.1, ZP_02635029.1, } \\
\text { ZP_02952453.1, ZP_02642534.1, } \\
\text { ZP_02863824.1 }\end{array}$ & 7 \\
\hline Clostridium sp. & ZP_09204362.1 & 1 \\
\hline Clostridium sporogenes & ZP_02995608.1 & 1 \\
\hline Clostridium tetani & NP_782216.1 & 1 \\
\hline Desulfovibrio fructosovorans & ZP_07334842.1 & 1 \\
\hline Desulfovibrio magneticus & YP_002953065.1 & 1 \\
\hline Dialister invisus & ZP_05734150.1 & 1 \\
\hline Megamonas funiformis & ZP_09733511.1 & 1 \\
\hline Megasphaera elsdenii & YP_004767129.1 & 1 \\
\hline Mitsuokella multacida & ZP_09733511.1,ZP_05405390.2 & 2 \\
\hline Parachlamydia acanthamoebae & ZP_06300753.1 & 1 \\
\hline Protochlamydia sp. & YP_008827.1 & 1 \\
\hline Selenomonas flueggei & ZP_04658998.1 & 1 \\
\hline Selenomonas infelix & ZP_09119488.1 & 1 \\
\hline Selenomonas noxia & ZP_06603000.1 & 1 \\
\hline Selenomonas sp. & ZP_07397197.1 & 1 \\
\hline Selenomonas sputigena & ZP_05898176.1 & 1 \\
\hline
\end{tabular}


Table 2. Biochemical characteristics of CPhy protein sequences determined by ProtParam server

\begin{tabular}{|c|c|c|c|c|c|c|}
\hline Accession number & Source organisms & $\begin{array}{l}\text { No. of } \\
\text { amino acids }\end{array}$ & $\begin{array}{l}\text { Molecular } \\
\text { weight }\end{array}$ & $\begin{array}{l}\text { Theoretical } \\
\text { pI }\end{array}$ & $\begin{array}{l}\text { Instability } \\
\text { index }\end{array}$ & $\begin{array}{l}\text { Aliphatic } \\
\text { index }\end{array}$ \\
\hline YP_003399467.1 & Acidaminococcus fermentans & 302 & 34098.8 & 9.3 & 31.84 & 79.26 \\
\hline YP_004897589.1 & Acidaminococcus intestini & 326 & 36785.4 & 9.57 & 37.13 & 80.25 \\
\hline ZP_03929107.1 & Acidaminococcus sp. & 332 & 37381.2 & 9.62 & 37.34 & 82.02 \\
\hline NP_968118.1 & Bdellovibrio bacteriovorus & 293 & 33549.3 & 8.65 & 43.78 & 77.2 \\
\hline ZP_08501473.1 & Centipeda periodontii & 328 & 37260.4 & 7.72 & 29.01 & 71.77 \\
\hline NP_149178.1 & Clostridium acetobutylicum & 319 & 36199.5 & 9.68 & 27.79 & 82.51 \\
\hline YP_001787593.1 & Clostridium botulinum & 820 & 94112.9 & 7.32 & 39.07 & 79.26 \\
\hline YP_002863193.1 & Clostridium botulinum & 820 & 93906.9 & 8.67 & 37.87 & 81.26 \\
\hline ZP_02614565.1 & Clostridium botulinum & 820 & 93926 & 8.88 & 39.86 & 79.84 \\
\hline YP_001391515.1 & Clostridium botulinum & 820 & 93922.8 & 8.78 & 39.08 & 78.88 \\
\hline YP_001781827.1 & Clostridium botulinum & 820 & 93882.9 & 8.72 & 39.73 & 80.2 \\
\hline YP_001254710.1 & Clostridium botulinum & 820 & 94022.1 & 8.83 & 39.34 & 80.44 \\
\hline ZP_02951610.1 & Clostridium butyricum & 309 & 35527 & 5.35 & 44.46 & 84.24 \\
\hline YP_001394001.1 & Clostridium kluyveri & 312 & 36206.7 & 9.01 & 40.77 & 76.15 \\
\hline YP_003781358.1 & Clostridium ljungdahlii & 343 & 40226.4 & 9.21 & 39.58 & 84.64 \\
\hline YP_003781970.1 & Clostridium ljungdahlii & 316 & 36271.8 & 8.96 & 38.07 & 81.65 \\
\hline YP_696211.1 & Clostridium perfringens & 308 & 35643 & 8.74 & 23.97 & 94.87 \\
\hline ZP_02633371.1 & Clostridium perfringens & 308 & 35662.9 & 7.76 & 24.37 & 94.25 \\
\hline NP_562440.1 & Clostridium perfringens & 308 & 35628.9 & 7.76 & 24.37 & 95.32 \\
\hline ZP_02635029.1 & Clostridium perfringens & 308 & 35610.9 & 7.76 & 22.85 & 96.79 \\
\hline ZP_02952453.1 & Clostridium perfringens & 308 & 35540.8 & 7.76 & 22.45 & 95.19 \\
\hline ZP_02642534.1 & Clostridium perfringens & 308 & 35555.8 & 7.76 & 22.85 & 95.84 \\
\hline ZP_02863824.1 & Clostridium perfringens & 308 & 35554.8 & 7.76 & 22.45 & 95.19 \\
\hline ZP_09204362.1 & Clostridium sp. & 820 & 93753.2 & 8.09 & 32.57 & 82.96 \\
\hline ZP_02995608.1 & Clostridium sporogenes & 820 & 93522.1 & 8.27 & 41.85 & 81.5 \\
\hline NP_782216.1 & Clostridium tetani & 307 & 35509.7 & 9.16 & 29.91 & 89.8 \\
\hline ZP_07334842.1 & Desulfovibrio fructosovorans & 283 & 31305.2 & 5.73 & 46.2 & 82.79 \\
\hline YP_002953065.1 & Desulfovibrio magneticus & 331 & 35004 & 10.19 & 44.77 & 88.34 \\
\hline ZP_05734150.1 & Dialister invisus & 408 & 46674.4 & 9.1 & 38.51 & 76.08 \\
\hline ZP_09733511.1 & Megamonas funiformis & 341 & 39558.9 & 8.21 & 28.77 & 81.55 \\
\hline YP_004767129.1 & Megasphaera elsdenii & 347 & 39486.4 & 4.79 & 42.89 & 69.14 \\
\hline ZP_05405389.1 & Mitsuokella multacida & 640 & 73136.4 & 9.06 & 29.94 & 74.22 \\
\hline ZP_05405390.2 & Mitsuokella multacida & 323 & 36779.8 & 9.16 & 35.9 & 70.99 \\
\hline ZP_06300753.1 & Parachlamydia acanthamoebae & 320 & 37249.7 & 6.46 & 39.84 & 90.5 \\
\hline YP_008827.1 & Protochlamydia sp. & 311 & 35620.6 & 7.16 & 38.55 & 89.29 \\
\hline ZP_04658998.1 & Selenomonas flueggei & 328 & 36888.7 & 7.25 & 28.98 & 72.38 \\
\hline ZP_09119488.1 & Selenomonas infelix & 328 & 37258.2 & 7.75 & 33.12 & 69.7 \\
\hline ZP_06603000.1 & Selenomonas noxia & 328 & 37329.3 & 8.68 & 26.82 & 69.39 \\
\hline ZP_07397197.1 & Selenomonas sp. oral taxon & 328 & 36818.5 & 6.99 & 31.55 & 70.64 \\
\hline ZP_05898176.1 & Selenomonas sputigena & 334 & 37515 & 4.76 & 38.84 & 75.48 \\
\hline
\end{tabular}

Table 3. Distribution of Superfamily among CPhy protein sequences determined using superfam server

\begin{tabular}{lllll}
\hline & $\begin{array}{l}\text { Motif } \\
\text { Motifs } \\
\text { present } \\
\text { in no. of } \\
\text { sequence }\end{array}$ & $\begin{array}{l}\text { Motif } \\
\text { width }\end{array}$ & & Amino acid sequence \\
\hline 1 & 40 & 50 & TDHKWPTDEMVDYFVQFVKSMPKDTWLHFHCQAGIGRTTTFMIMYDMMKN & PTPc superfamily \\
2 & 40 & 29 & ICIVDLRQESHGFINGYPVSWYGEHNWAN & No putative conserved domains \\
3 & 40 & 29 & PNREGLDTLNISGSQQFSPQNLPLLVKSI & No putative conserved domains \\
4 & 40 & 29 & PPQTIIPTKVMTEEQLVEHNGMRYVRIPV & No putative conserved domains \\
5 & 16 & 41 & ADEIINRQLALAGFDEKHMKSFPNKERHDFFQKFYEYVKEQ & No putative conserved domains \\
6 & 8 & 50 & HYVTFIMSDGDNQQWNLGTNYGSPKWYGSPYRGNFNLGWSLSPSLYYLAP & GxGYxYP superfamily \\
7 & 8 & 50 & RDKVFSSMDPNSICLGWGPDEFINVSTSSKHGVSMIAADWSYNLTVLSAF & GxGYxYP superfamily \\
8 & 8 & 50 & KIPTHLYVISQNKMTSSERTMIATLQGIVNNHCSHQIYTLNSSQPDYQIW & GxGYXYP superfamily \\
9 & 8 & 50 & FYNNKLWDKFTVKPNIQGLFYLDYRKHNNYHGEIIWSNNKPIVSCRDLLW & GxGYxYP superfamily \\
10 & 8 & 50 & GDCRNTDKDWAYNNLWNSGLNHSIVIQLSPEKETALRDYAIMTKSLIFYE & GxGYXYP superfamily \\
\hline
\end{tabular}




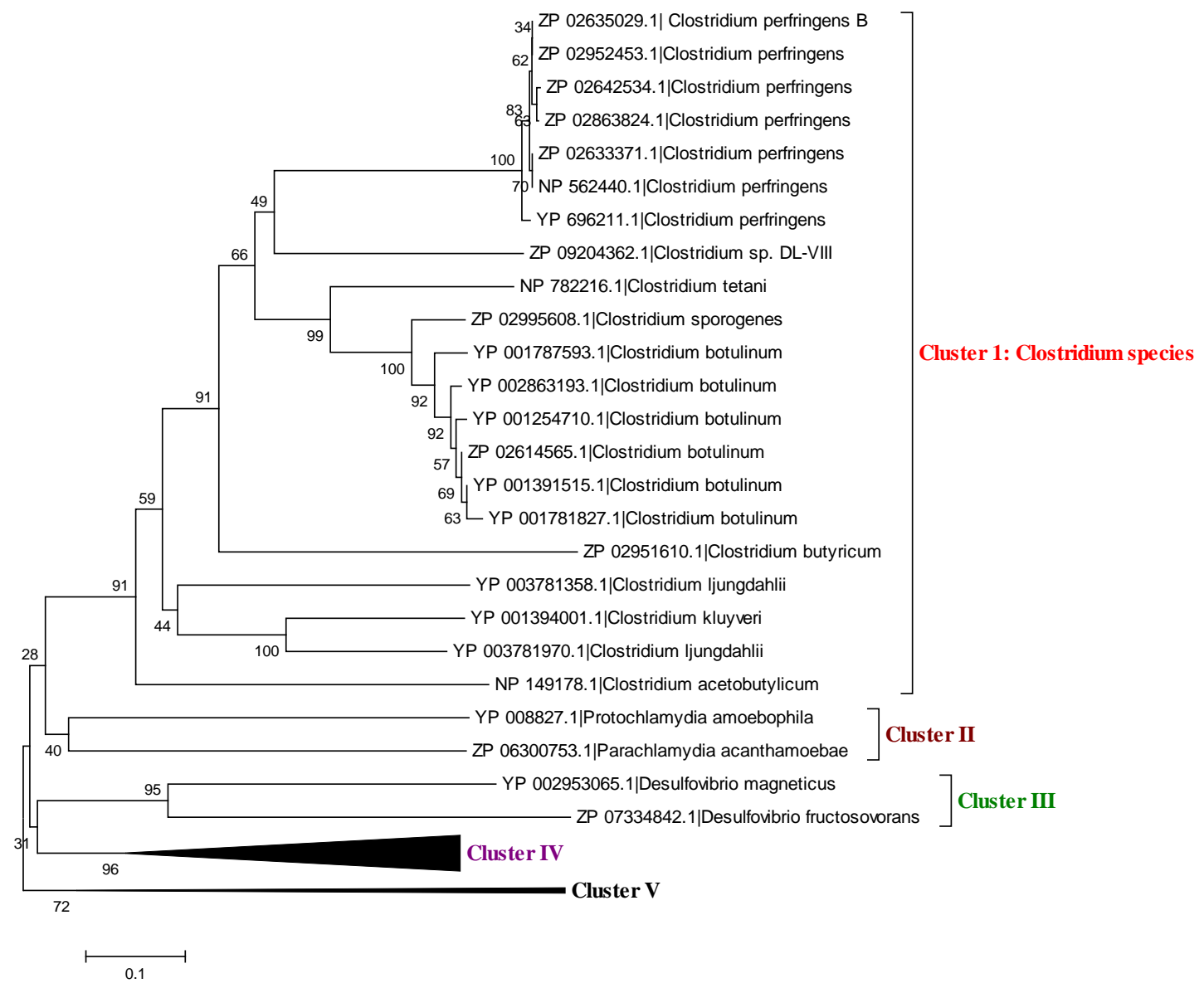

Figure 1.A. Phylogenetic tree constructed by NJ method based on CPhy protein sequences

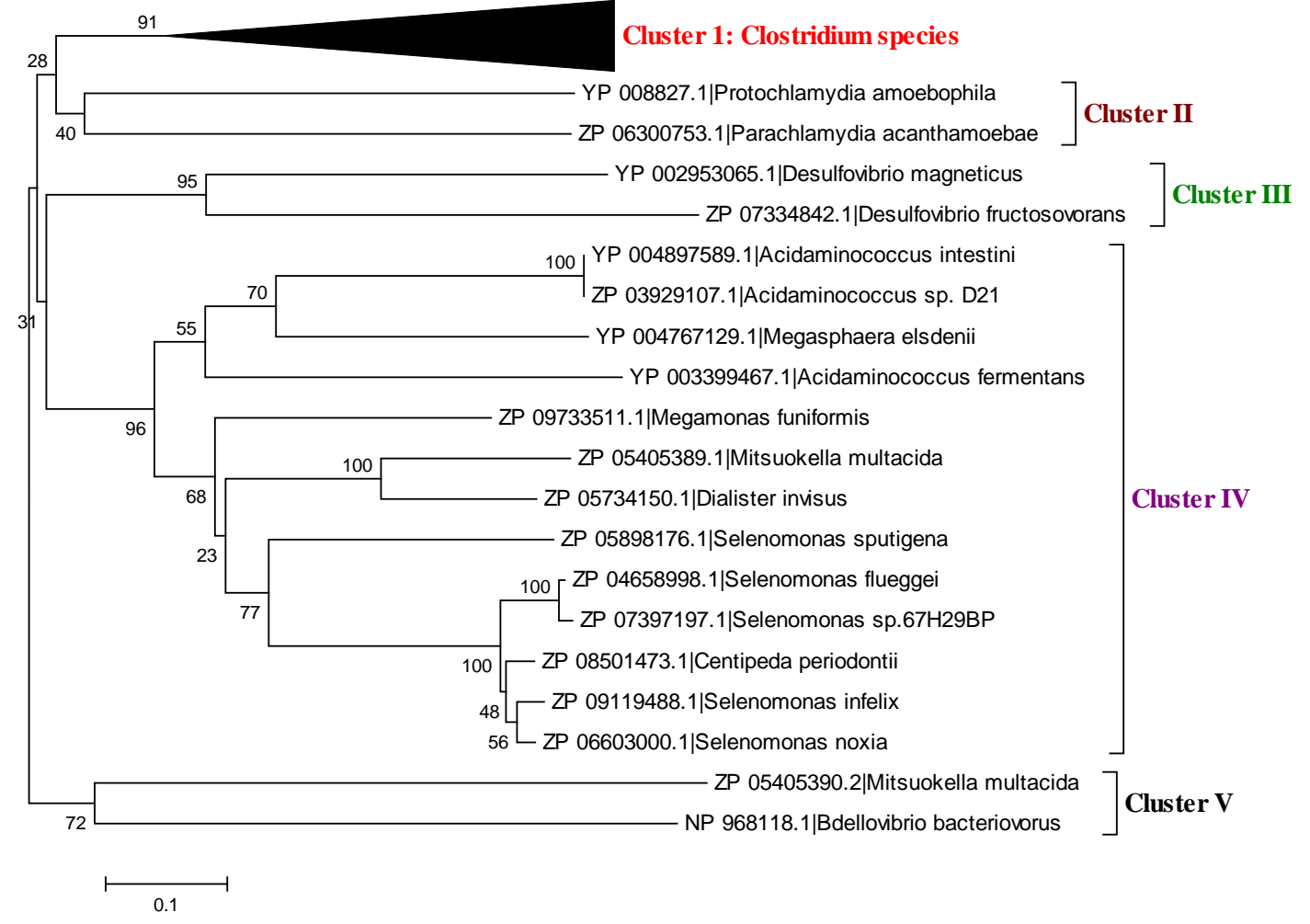

Figure 1.B. Phylogenetic tree constructed by NJ method based on CPhy protein sequences 
aliphatic index increases protein thermostability (Atsushi 1980; Rawlings et al. 2006). Aliphatic index of CPhy protein sequences was observed in the range of 70-95, suggesting sequences were varied in their thermostability (Table 2). Superfam analysis revealed the presence of 'phosphotyrosine protein phosphatase II superfamily' and 'myo-inositol hexaphosphate phosphohydrolase PhyA family' in all 40 protein sequences. Protein tyrosine phosphatases (PTP) catalyze the dephosphorylation of phosphotyrosine peptides; they regulate phosphotyrosine levels in signal transduction pathways. The depth of the active site cleft renders the enzyme specific for phosphorylated Tyr (pTyr) residues, instead of pSer or pThr.

Analysis of 10 motifs by MEME suite with provided parameters revealed 50 amino acids long motif ' 1 ' 'TDHKWPTDEMVDYFVQFVKSMPKDTWLHFHCQA GIGRTTTFMI MYDMMKN' was present in all cysteine phytase protein sequences. The functional domain found in this motif was similar to PTPc superfamily. This family has a distinctive active site signature motif, HCSAGxGRxG, characterized as either transmembrane, receptor-like or non-transmembrane (soluble) PTPs. Receptor-like PTP domains tend to occur in two copies in the cytoplasmic region of the transmembrane proteins, only one copy may be active. Other motifs (6 to 10) were found similar to GxGYxYP superfamily. This family carries a characteristic sequence motif, GxGYxYP, but is of unknown function. Associated families are sugar-processing domains. Complete list of motifs with their characteristics is given in Table 3.

In conclusion, this in silico study for phylogenetic clustering, conserved motifs sequences and biochemical features of phytases from class CPhy, could be key information for their further classification and genetic modification within key sequence features for the development of novel phytase with desired properties. Conserved motif sequences are important for conserved primer design and diversity study thereafter.

\section{ACKNOWLEDGEMENTS}

The authors gratefully acknowledge Department of Science and Technology for providing infrastructural facility in the form of DST-FIST grant to Department of Biochemistry, G.B. Pant University of Agriculture and Technology, India. Lead author is grateful to Indian Council of Agriculture Research (ICAR), for providing financial assistance in the form of ICAR-SRF.

\section{REFERENCES}

Atsushi I. 1980. Thermostability and aliphatic index of globular proteins. J Biochem 88: 1895-1898.

Chu HM, Guo RT, Lin TW, Chou CC, Shr HL, Lai HL, Tang TY, Cheng KJ, Selinger BL, Wang AHJ. 2004. Structures of Selenomonas ruminantium Phytase in Complex with Persulfated Phytate: DSP Phytase Fold and Mechanism for Sequential Substrate Hydrolysis. Structure 12: 2015-2024.

Denu JM, Dixon JE. 1998. Protein tyrosine phosphatases: mechanisms of catalysis and regulation. Curr Opin Chem Biol 2: 633-641.

Guruprasad K, Reddy BVB, Pandit MW. 1990. Correlation between stability of a protein and its dipeptide composition: a novel approach for predicting in vivo stability of a protein from its primary sequence. Protein Engineer 4: 155-161.

Hegeman CE, Grabau EA. 2001. A novel phytase with sequence similarity to purple acid phosphatases is expressed in cotyledons of germinating soybean seedlings. Plant Physiol. 126: 1598-1608

Kumar V, Sangwan P, Singh G, Verma AK, Agrawal S. 2014a. Cloning, sequencing, expression and in silico analysis of $\beta$-propeller phytase from Bacillus licheniformis strain PB-13. Biotech Res Internat 2014: 1-11, Article ID 841353, DOI: 10.1155/2014/841353

Kumar V, Sangwan P, Verma AK, Agrawal S. 2014b. Molecular and Biochemical Characteristics of Recombinant $\beta$-Propeller Phytase from Bacillus licheniformis Strain PB-13 with Potential Application in Aquafeed. Appl Biochem Biotechnol DOI 10.1007/s12010-0140871-9.

Kumar V, Singh G, Verma AK, Agrawal S. 2012. In silico characterization of histidine acid phytase sequences. Enzyme Res 2012: 1-8, 845465, DOI: 10.1155/2012/845465

Kumar V, Singh P, Jorquera M, Sangwan P, Kumar P, Verma AK, Agrawal S. 2013. Isolation of phytase-producing bacteria from Himalayan soils and their effect on growth and phosphorus uptake of Indian mustard (Brassica juncea). World J Microbiol Biotech 29: 1361-1369.

Lei XG, Weaver JD, Mullaney E, Ullah AH, Azain MJ. 2013. Phytase, a new life for an "old" enzyme. Annu Rev Anim Biosci 1(1): 283-309.

Mullaney EJ, Ullah AH. 2003. The term phytase comprise several different classes of enzymes. Biochem Bioph Res Co 312: 179-184.

Pannifer ADB, Flint AJ, Tonks NK, Barford D. 1998. Visualization of the cysteinyl-phosphate intermediate of a protein-tyrosine phosphatase by X-ray crystallography. J Biol Chem 273: 10454-10462.

Puhl AA, Gruninger RJ, Greiner R, Janzen TW, Mosimann SC, Selinger LB. 2007. Kinetic and structural analysis of a bacterial protein tyrosine phosphatase-like myo-inositol polyphosphatase. Protein Sci 16: $1368-1378$

Rawlings ND, Morton FR, Barrett AJ. 2006. MEROPS: the peptidase database. Nucleic Acids Res 34: 270-272.

Rogers S, Wells R, Rechsteiner M. 1986. Amino acid sequences common to rapidly degraded proteins: the PEST hypothesis. Sci 234: 364.

Sapna, Singh B, Singh D, Sharma KK. 2013. Microbial Phytases in Skirmishing and Management of Environmental Phosphorus Pollution. In: Biotechnology for Environmental Management and Resource Recovery. Springer India.

Sechi S, Chait BT. 1998. Modification of cysteine residues by alkylation. A tool in peptide mapping and protein identification. Anal Chem 70: 5150-5158.

Singh P, Kumar P, Agrawal S. 2014. Evaluation of phytase producing bacteria for their plant growth promoting activities. Intl J Microbiol 2014: 1-7, Article ID: 426483, DOI: $10.1155 / 2014 / 426483$

Tamura K, Peterson D, Peterson N, Stecher G, Nei M, Kumar S. 2011. MEGA5: molecular evolutionary genetics analysis using maximum likelihood, evolutionary distance, and maximum parsimony methods. Mol Biol Evol 28: 2731-2739.

Yanke L, Selinger L, Cheng KJ. 1999. Phytase activity of Selenomonas ruminantium: a preliminary characterization. Lett Appl Microbiol 29: 20-25.

Zhang ZY, Zhou B, Xie L. 2002. Modulation of protein kinase signaling by protein phosphatases and inhibitors. Pharmacol Therapeut 93: 307317.

Zhang ZY. 2003. Mechanistic studies on protein tyrosine phosphatases. Prog Nucl Acid Res Mol Biol 73: 171-220.

Zhou MM, Logan TM, Theriault Y, Van Etten RL, Fesik SW. 1994. Backbone $1 \mathrm{H}, 13 \mathrm{C}$, and $15 \mathrm{~N}$ assignments and secondary structure of bovine low molecular weight phosphotyrosyl protein phosphatase. Biochem 33: 5221-5229. 